

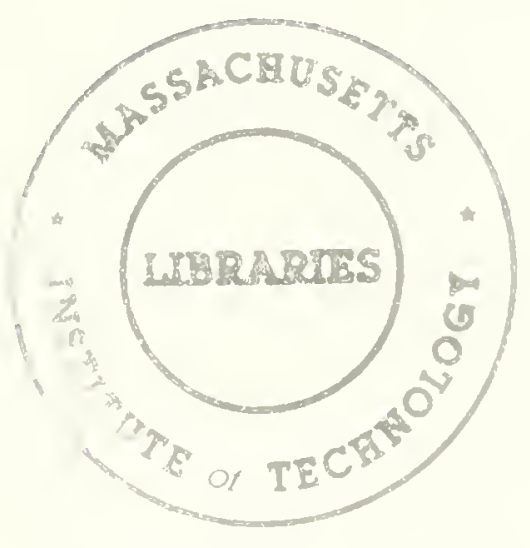






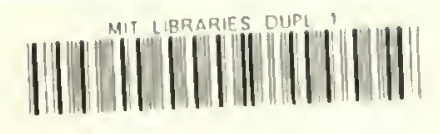

$39080 \quad 00656848 \quad 6$

\section{WORKING PAPER}

ALFRED P. SLOAN SCHOOL OF MANAGEMENT

Informal Technology Transfer Between Firms:

Cooperation Through Information Trading

Stephan Schrader

May, 1990

WP\# BPS-3153-90

\section{MASSACHUSETTS}

INSTITUTE OF TECHNOLOGY

SO MEMORIAL DRIVE

CAMBAIDGE, MASSACHUSETTS 02139 


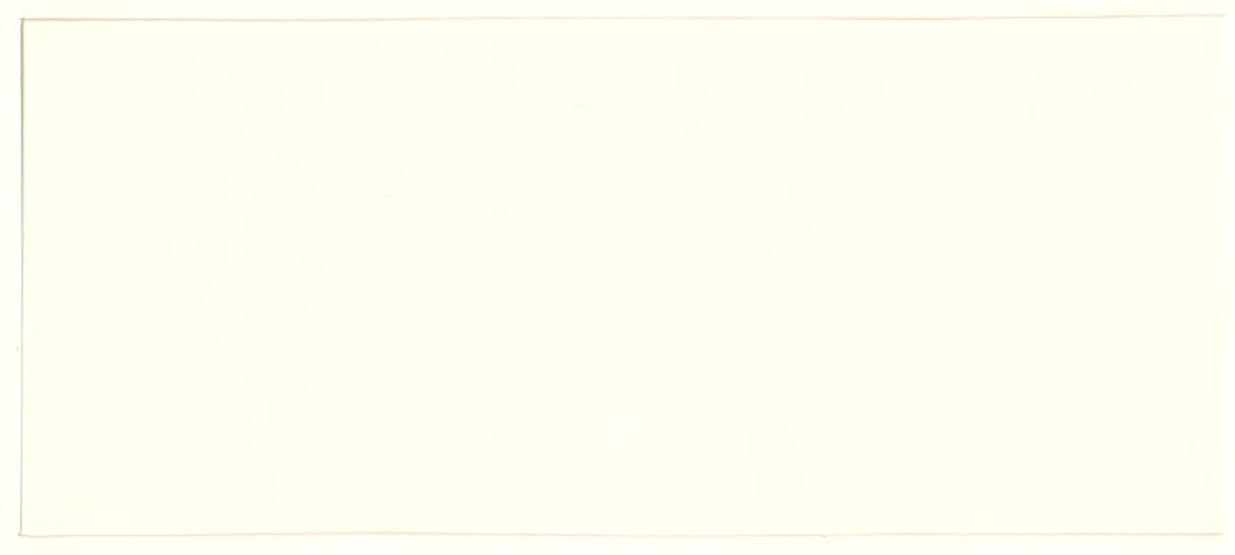


Informal Technology Transfer Between Firms:

Cooperation Through Information Trading

\section{Stephan Schrader}

May, 1990

WP\# BPS-3153-90

Massachusetts Insitute of Technology

Sloan School of Management

50 Memorial Drive, E52-553

Cambridge, MA 02139 

RELi: $: !$ 


\title{
Informal technology transfer between firms: \\ Cooperation through information trading *
}

\author{
Stephan Schrader
}

Employees frequently give technical information or advice to colleagues in other firms, including direct competitors. This paper addresses whether this information transfer is in the economic interests of the firms involved.

It is hypothesized that employees trade information within the economic interests of their firms. Conditions are discussed in which information trading creates an economic advantage to the participating firms.

Data on specific information transfer decisions were obtained from a survey of 294 technically oriented middle-level managers from the U.S. specialty steel and minimill industry. The observed pattern of information transfer strongly supports the hypotheses (1) that employees trade information, and (2) that such trading is desirable from a firm's point of view. Furthermore, the data suggest a positive link between the participation of a firm's employees in informal information-transfer networks and the economic performance of the firm. Indeed, it can be in a firm's interest to make its boundaries penetrable for informal information transfer rather than to discourage such transfers.

- I thank Eric von Hippel and Eberhard Witte for their support and advice, Anne Carter, Dictmar Harhoff, Henrik Sattler, and Marcy Tyre for their helpful comments and suggestions, and Stephanie Kaylin for her editorial help. 



\section{Introduction}

The importance of informal communication networks for the diffusion of technical information is demonstrated by several studies (e.g. Czepiel 1974, Bradbury et al. 1978, Allen 1984). Analyzing information transfer in the semiconductor industry, Rogers (1982, pp. 115-116) concludes that although formal, official channels exist for the exchange of technical information, "the most valuable information is communicated mainly via informal channels." Von Hippel (1987) suggests that employees actually trade information within these networks. Individual employees provide information to colleagues from other firms with the expectation of receiving valuable information in return, either immediately or in the future. Observing similar exchange relationships in the semiconductor industry, Rogers $(1982$, p. 114) at least partly explains employees' willingness to disclose useful information to other firms by the fact "that information must be given in order for it to be obtained," and he gives examples of individual employees who trade information while keeping the economic interests of their firms in mind.

Most economic and management researchers, however, regard informal information transfer between firms as a disadvantage for firms. Mansfield (1985, p. 219), for example, labels this type of transfer "leakage of information." He argues that the rapid diffusion of technology via informal channels is one reason many firms have difficulty appropriating the benefits from their innovations. As Rogers (1982) points out, primarily non-economic motives may be crucial to the decision whether to disclose information to a colleague from another firm. An employee's information-transfer behavior may be driven by purely personal objectives, which may conflict with the interests of his or her firm. A personal friendship, for example, might overrule economic considerations. The importance of friendship and trust for the disclosure of information has been demonstrated by several studies, both in the business world (e.g. 
Saxenian 1985, Sitkin 1986) and outside this context (e.g. Berg and Clark 1986, Miell and Duck 1986).

In order to understand how firms should manage informal information transfers, it has to be determined whether it constitutes information leakage or information trading. If the transfer is leakage, then firms might well want to prevent it. If it is trading, firms might well support it.

This paper first characterizes information trading. It then discusses information trading as an economically motivated exchange. Circumstances are investigated under which information trading is economically advantageous for firms. Next, methods are described that were used to study informal information transfer in the chosen industry, the U.S. specialty steel and mini-mill industry, and the results of this study are presented. The empirical evidence supports the notion that, in the industry investigated, employees trade information within the economic interests of their firms. Finally, ways in which these results might change aspects of our understanding of characteristics firm boundaries are discussed.

\section{Description of information trading}

Information trading refers to the informal exchange of information between employees working for different, sometimes directly competing firms (von Hippel 1987). Employees provide colleagues working at other firms with technical advice in the expectation that their favors will be returned in the future. To illustrate the process, consider a medium-sized steel mini-mill in which a new continuous caster was installed. (A continuous caster is used to cast liquid steel into semifinished products, such as billets, which are transformed by later process steps into mill products, such as bars and wires.) Unforeseen technical difficulties in the start-up process were encountered. The superintendent responsible activated his network of personal 
contacts by calling up a colleague who worked for a directly competing firm; the two men meet frequently at meetings of the Association of Iron and Steel Engineers. The colleague, whose firm was using the same piece of equipment, had to decide whether to provide the information requested. In this case, he provided the needed help, and the technical problem was solved swiftly. (If he had thought that providing the information would create a disadvantage for his firm, he probably would have refused the request.) The superintendent who received the help knew that he was incurring an obligation to provide similar assistance in the future. Reciprocity appears to be one of the fundamental rules governing information trading.

Such informal transfer of technical information between firms is a frequent and important phenomenon (e.g. Martilla 1971). Allen (1984) shows that personal contacts with colleagues working in other firms are of considerable importance to the performance of technical development projects (see also Katz and Tushman 1981). In a study of the diffusion of a major technical innovation, Czepiel (1974, p. 178) observes the existence of "a functioning informal community linking together the firms" based on word-of-mouth communication.

These observations are confirmed by my empirical investigation of informal information transfer in the U.S. specialty steel and mini-mill industry. The methodology and results of the study are discussed in sections 4 and 5. At this point, however, data demonstrating the significance of informal information transfers are presented. The surveyed middle-level managers and engineers were asked to indicate the importance of colleagues in other steel firms as a source of technical information. Sixty-one percent of the 294 respondents considered colleagues in other firms to be an important or even very important information source, i.e., they indicated a value of at least 5 on a 7-point scale, with 1 meaning "not at all important" and 7 meaning "very important" (fig. 1). 


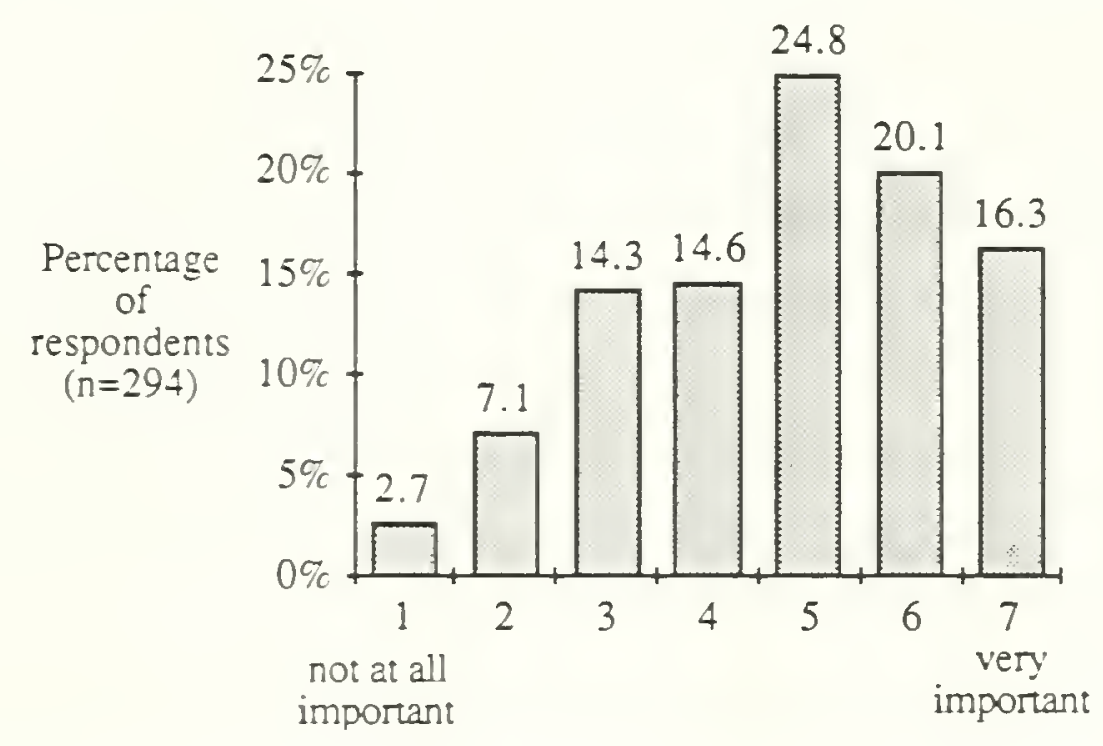

Figure 1: Importance of informal information transfer between firms for respondents

In comparison with other possible information sources (colleagues within the same firm, vendors, customers, professional journals and books, and presentations at conferences), only colleagues within the same firm are considered, on average, to constitute a significantly more important information source than colleagues at other firms.

External contacts are not only an important information source for the employees surveyed; these employees themselves are sought after as information providers. Eighty-five percent reported that, at least once during the year before the survey, they had been asked by a colleague working in another firm for some specific technical information. Nineteen percent had been asked 10 or more times. Of all the employees who had been sought after as an information source by their colleagues, only 2 percent had never provided the desired information. Altogether, 83 percent of the employees surveyed had provided information at least once during the period of investigation to colleagues in other steel firms. 


\section{Information trading as economic exchange}

Under what circumstances can information trading be expected to be in the economic interests of the involved firms? Von Hippel (1987) argues that, in principle, information trading could benefit firms if employees adhere to certain guidelines with respect to what they do and do not trade.

It is advantageous to trade information if the information offers "relatively little competitive advantage" (von Hippel 1987, p. 298). In this context, competitive advantage is defined as "the extra increment of rent which the firm can expect to garner if it does not trade the unit of proprietary know-how" (ron Hippel 1987, p. 298; see also Carter 1989). This extra increment of rent depends on the specific situation. The same information might offer a great competitive advantage relative to one firm, but no competitive advantage, or only a small one, relative to another. Providing this information to the first firm reduces the information provider's expected rents to a considerable extent, whereas providing the information to the second firm changes the rent expectations only slightly: Thus it is conceivable that transferring information to another firm creates little costs to the providing firm even if the information is generally of high value to the latter. In such situations, trading this information for similar information can benefit both trading partners.

Take, for example, two firms $A$ and $B$ that compete primarily on product quality. Assume firm A possesses information that could help both firms to simplify the production process but not to improve product quality. Even if A provides this information to $B, A$ still benefits from the simplification. In other words, the rent that $A$ expects to draw from this information is largely unaffected by whether firm B also know's the information. Transferring the information creates little costs to A. ${ }^{1}$ Firm B, however, might benefit greatly from receiving the information, creating an obligation to

1 Transferring this information creates costs for firm A only if the resultang costs savings induce $B$ to finance measures that affect $A$ inversely and that would not have been financed otherwise. 
reciprocate information that could benefit $A$ in turn. Thus both firms would gain from trading this type of information. The following subsections discuss the costs and benefits of trading information in greater detail.

\subsection{Cost of transferring information}

Transferring information generates costs for the transferring firm if the transfer lessens part of the firm's competitive advantage originating from possessing the information (Carter 1989). ${ }^{2}$ To put it differently, the cost of transferring information equals the amount by which the firm's rent expectation changes if the information receiver also know's the information - everything else being equal and abstracting from the costs of the diffusion process itself. Here three factors are discussed that should influence the degree to which an information transfer affects the rent expectations of the transferring firm: (1) the degree of competition between the involved firms, (2) the availability of alternative information sources, and (3) whether the information relates to a domain in which the involved firms compete.

Degree of competition: The rent that a firm can expect to gain from a specific unit of information is likely to remain unchanged by disclosure of the information to a noncompetitor - provided the receiving firm does not give the information to another firm that is a competitor. Cooperation between partners with diverging competitive goals allow's one partner to benefit without the other partner losing (Hamel, Doz, and Prahalad 1989). Can the transferring firm expect the information receiver not to disseminate the information further? Anecdotal evidence drawn from interviews conducted with technical managers in the steel industry during the pilot phase of this research project suggests an industry norm: information that one firm receives from another firm should not be given to a third firm. What the information receiver can do

2 Transferring information also leads to transaction costs. These costs are neglected in the following argument since they can be expected to be insignificant (Carter 1989). 
is to tell third parties that the specific piece of technical know-how is available, referring them to the original source. This norm ensures that transferring information to another firm does not necessarily turn the information into a public good. Given these circumstances, a firm is unlikely to experience a considerable "competitive backlash" (Carter 1989) when disclosing useful information to a noncompetitor.

A different situation exists if the receiving firm is a competitor. Take, for example, the disclosure of some information to a competing firm that puts the recipient in a position to improve product quality without increasing cost; assume that the two firms compete with regard to product quality. Receiving this information enables the competitor to improve its position in the marketplace. In such a situation, the rent expectations of the original owner of the information must be revised downwards. This specific information no longer gives its owner a competitive advantage relative to the information receiver. Thus transferring information to a competitor entails greater costs than transferring information to a noncompetitor.

Under certain circumstances, however, providing information to a competitor means little or no cost for the information provider, especially if the inquirer could have received similar information without great difficulty from another source, or if the transferred information does not relate to a dimension on which the firms compete with each other.

Availability of alternative information sources: The degree to which a transfer changes the rent expectations of the transferring firm partly depends on the time span for which the information would have given its original owner a know-how advantage relative to the inquirer (Porter 1983). The shorter this time span, the smaller the change in value of the information caused by a transfer, all else being equal.

Often, proprietary know-how can be independently developed by any competing firm that needs it, given an appropriate expenditure of time and resources (Teece 19S6, von Hippel 1987). In a survey of 650 high-level R\&D managers representing 130 lines of 
business, most of the respondents indicated that other firms can duplicate typical unpatented process and product innovations within a reasonable time span, and at costs considerably less than that of the innovator (Levin, Klevorick, Nelson, and Winter 1987, p. 809). In addition, similar know-how frequently can be obtained from other sources for example, from suppliers or from other firms in the same industry. In these cases, the competitive advantage caused by an informational lead would probably be lost even if the firm had refused to transfer the information.

Consequently, if the receiving firm could easily develop the same or similar know-how internally or if similar information is available to the receiving firm from other sources, transferring information reduces a firm's rent expectations only slightly.

Impact of information on domains of competitive importance: Firms may compete with each other on several dimensions - for example, product quality, product price, and customer service. Transferring information tends not to alter the competitive relationship between the information-providing and the informationreceiving firm, assuming the information relates to a domain in which the firms do not compete with each other (Hamel, Doz, and Prahalad 1989). Thus handing over such information creates little or no costs for the information-providing firm; the firm's competitiveness is not diminished. Nevertheless, obtaining this information may benefit the receiving firm considerably. In the steel industry, transferring information that helps firms improve product quality (e.g. how to control specific parameters of the melting process so as to reduce the occurrence of lead strings in the rolled steel) tends to be more damaging for a firm's competitive position, relative to the information receiver, than is transferring information that leads to a reduction in production cost. Why should this be? Steel firms compete primarily in three dimensions: product quality, price, and service (Barnett and Crandall 1986). Supplying a competitor with quality-related information helps that competitor improve on a dimension of competition - product quality - and is therefore disadvantageous for the transferring 
firm. Through enabling a competitor to produce and sell a better product, the transferring firm puts its own competitive position at risk.

On the other hand, transferring cost-related information (e.g. how to improve lubrication of the fabric bearings of a rolling mill so that their pass life increases) is less likely to be disadvantageous. In the steel industry, prices are set quite independently from marginal costs. The large proportion of fixed costs and the high barriers to exit are responsible for the fact that it is often more economical for firms to sell their products below cost than to leave expensive capacity unutilized. Thus information leading to cost savings will contribute to the improvement of a firm's profit margin but will not necessarily lead to a price decrease. A notable exception is radical cost savings large enough to allow strategic price cuts that cannot be matched by competitors (Porter 1985). Therefore a transfer of nonradical cost-saving information is unlikely to create a disadvantage for the transferring firm, provided the receiving firm does not use the additional profit to finance measures detrimental to the transferring firm that would not have been financed otherwise.

\subsection{Benefit of transferring information}

Up to this point, the argument has concentrated on the extent to which transferring a specific unit of information may reduce a firm's rent expectations. That is, the analysis has been limited to the cost of transferring information; it has been shown that under some circumstances firms can transfer valuable information at little or no cost to themselves. Next, let us investigate the benefits connected with information transfer.

Empirical evidence by von Hippel (1987) and Rogers (1982) suggests that transferring information is part of exchange relationships grounded in reciprocity. In exchange relationships, providing another party with a favor obliges that party to reciprocate in order to maintain the balance of benefits and contributions, even without 
an explicit agreement (e.g., Macaulay 1963, Levine and White 1961, Miller and Berg 1984). Several studies offer support for the strength and extent of the quid pro quo norm (see the overviews presented in Gross and McMullen 1982 and Miller and Berg 1984). There are two partly overlapping approaches for explaining this norm. The first approach argues that a party receiving a benefit would weaken the relationship if it did not return the favor, thereby lessening its own chance of receiving possible benefits in the future. This perspective assumes that the players are interested in continuing the relationship (e.g. Blau 1964). The second approach proposes that social regulative mechanisms are responsible for balancing benefits and contributions: "The social costs of receiving help involve either the obligation of repayment, or if no reciprocity is intended, the penalty, at least for middle-class North Americans, of attendant guilt feelings" (Gross and McMullen 1982, p. 321).

Independent of how the dynamics of exchange relationships are explained, the literature proposes, first, that receiving a benefit is likely to increase the probability that the receiver will provide a similar benefit in the future. Second, the literature suggests that the change in the receiver's willingness to provide a benefit depends on the value of the benefit that he or she received (e.g. Blau 1964, Adams 1965, Walster, Berscheid and Walster 1976, Emerson 1976, Mills and Clark 1982, Clark, 1985). Thus, if informal information transfers constitute exchange relationships, then the benefit of providing information depends on the degree to which giving help increases the chance of receiving help. This in turn depends on the value of the provided information to the receiver: the more important the information to the receiver, the stronger his or her obligation to reciprocate, and the greater the future benefit for the information provider.

Nonetheless, even if the information receiver is eager to reciprocate, this cooperation is without benefit to the information provider if the former cannot return information of relevance to the latter. This leads Carter $(1989, \mathrm{p} .157)$ to propose that a trader might "favor partners that promise the most useful information in return for his 
own." Consequently, it should be more in the interest of a firm to exchange information with another firm at the forefront of technological development than to maintain an information-exchange relationship with a firm barely managing to keep up with technological advances.

Table 1, which summarizes the preceding discussion, lists the variables expected to influence an employee's decision about whether to provide information to a colleague in another firm, assuming that the employee trades information according to the economic interest of his or her firm firm. The empirical analysis presented in sections 4 and 5 tests whether employees orient their information exchange behavior along the variables discussed.

Table 1: Hypothesized influence of discussed variables on employees' decision whether to transfer information to colleagues from other firms

Variables

Influencing the costs of transferring information

- Degree of competition between information providing firm and information receiving firm

- Availability of alternative information sources to information receiver

- Information's impact on domains of high competitive importance

Influencing the benefits of transferring information

- Likelihood that information receiver will reciprocate information

- Value of transferred information to information receiver

- Technical expertise of information receiver

Likelihood of a transfer of requested

information if variable

takes on high value

less likely

more likely

less likely

more likely

more likely

more likely 


\section{Methods}

The empirical investigation concentrates on the U.S. specialty steel and mini-mill industry, a segment chosen because it is characterized by considerable non-radical technical advance. Although the focus on this industry has the obvious disadvantage that the results are not easily generalizable, preliminary evidence from research in industries such as aerospace and oil exploration suggests that the patterns found apply also to these industries (Gavilis, 1989).

An example of the technological advance in the mini-mill industry is provided by a 70 percent reduction in the average tap-to-tap time from 1975 to 1985 . (The tap-totap time is a parameter describing the efficiency of the melting process.) During this same period, average man-hours per ton fell by 47 percent (Barnett and Crandall 1986, p. 57). This progress, however, is not due to radical technical change. The basics of the underlying technologies (electric arc furnace, continuous caster, rolling mill) remained unchanged during those 10 years. Rather, the continuous improvement of existing technology was the key to the industry's progress (Barnett and Crandall 1986). Consequently, information about small improvements, which is often transferred informally, has a significant impact on firm performance in this industry.

Data on the information transfer behavior of employees was collected by a mail questionnaire. The data analysis employs primarily two methods: (1) factor analysis for data reduction and (2) probit analysis for testing whether it is possible to discriminate systematically between situations in which employees are willing to trade technical information and those in which they refuse to do so. 


\subsection{Data collection}

A mail questionnaire was used to learn about employees' decisions whether to transfer information to colleagues in other firms, and to test whether informal information transfers are part of information-trading relationships.

The questionnaire was sent to 477 technical managers, all of those listed under one of the 127 specialty steel or mini-mill companies appearing in the 1986 Directory of Iron and Steel Plants ${ }^{3}$ and identified by their job title as being directly responsible for technical aspects and not belonging to top management. Typical job titles are plant manager, superintendent of the rolling mill, superintendent of the meltshop, and chief engineer. Top-level managers were not included in the sample since the pilot study had led to the conclusion that such managers do not participate actively in the exchange of technical information. (They appear, however, to frequently exchange other kinds of information, for example, expectations about general market developments.)

In the questionnaire, half the employees surveyed were asked to think back to the last instance in the past year when someone from another steel firm had requested technical information and they had provided the desired information (version 1 of the questionnaire: transfer situation). The other half of the respondents were asked to think back to the last instance when they had been asked for information and had not provided it (version 2: no-transfer situation). Both situations were to be described in terms of the same variables, using primarily 7 -point scales.

The idea behind this approach was to collect two samples, one consisting of cases in which employees are willing to transfer information; the other, of cases in which employees refuse to transfer information. Using these two samples, transfer and no-

3 The directory, considered by industry experts to be a comprehensive source, lists specialty steel companies, minimills, and integrated steel companies by type, providing the names and titles of topand middle-level managers in each firm. 
transfer situations could be compared systematically, and the variables that help discriminate between transfer and no-transfer situations could be identified.

This approach avoided the need for employees to provide explanations or general descriptions of their information-transfer behavior, thereby reducing problems resulting from postrationalization of behavior and from misperceptions about average behavioral tendencies. The questionnaire inquired about each employee's last information-transfer decision - not about a typical decision. The former approach is likely to result in a representative sample of transfer decisions while the latter probably would lead to a biased sample.

Most of the questions related to the variables hypothesized to influence information-transfer decisions. The questions and their phrasing were strongly influenced by an extensive pilot study consisting of open interviews with 44 managers and technical employees from the same industry. Twenty of the 44 managers interviewed in the pilot study were selected at random from the 1986 Directory of Iron and Steel Plants; this random sample was supplemented by 24 additional employees, chosen either because they might help answer specific research questions or because other interviewees identified them as having a well-informed or an unusual understanding of the steel industry. The pilot-interviews concentrated on two subjects. The interviewees were asked to give examples of typical situations in which they do or do not transfer information to colleagues working for other steel firms. They were also asked to explain their specific transfer behavior and to speculate about the transfer behavior of their colleagues.

Let us illustrate the process used to formulate the questions by an example: In section 3.1, it was hypothesized that employees are more likely to transfer information if alternative information sources are available to the inquirer. In the pilot study, one interviewee described the following case. His firm had found a way to increase the life span of the refractor lining of the electric arc furnace by using newly developed 
refractory bricks, an approach that led to considerable cost savings. The respondent provided the information to colleagues at other firms because he expected them also to learn about the new bricks and details of their usage from other sources (especially from the manufacturer of the refractory bricks). Another pilot-study interviewee said that he exchanges information if he "can be sure that someone else will find the same or a similar solution in the near future." These and similar statements led to the construction of two questions referring to the availability of alternative information sources. These questions, and the scale used, are provided in fig. 2.

\section{Sample Questions}

Please indicate to which extent the following statements are accurate descriptions of the information the other person asked for.

$\begin{array}{ccc}\text { not at all } & \text { somewhat } & \text { very } \\ \text { accurate } & \text { accurate } & \text { accurate }\end{array}$

He could have gotten this kind of information from another source, for example, from another steel company or from a vendor.

$\begin{array}{lllllll}1 & 2 & 3 & 4 & 5 & 6 & 7\end{array}$

It would have been easy' for him to come up with a similar solution.

$\begin{array}{lllllll}\text { I } & 2 & 3 & 4 & 5 & 6 & 7\end{array}$

Figure 2: Format of the questions

In addition to hypothesis-driven questions, other questions measured aspects that some pilot-study interviewees had pointed out as important to their transfer decisions but that do not related in an obvious way to the stated hypothesis. Most of these variables relate to characteristics of the personal relationship between the employees participating in the information exchange. For example, some employees claimed that the length of time they have known the inquirer is important when deciding whether to provide help. Consequently, the variable "duration of relationship," measured by the 
question "For approximately how many years have you known this person?," was included in the questionnaire. Tables 2 and 3 contain the variables used to describe the context of a specific transfer decision and to characterize the information requested by the inquiring party. (See Schrader, 1990, for a more detailed discussion of the variables.)

Finally, the questionnaire collected demographic data on the employee, firm specific data, and data regarding the employee's perception of his or her average information transfer activities - for example, an estimation of the frequency with which he or she is contacted by colleagues from other firms for technical advice.

The questionnaire was mailed to the 477 selected managers in August 1987. In 29 cases, the employee could not be reached or had retired. Of the 448 employees reached, 297 returned the questionnaire. Three questionnaires had to be discarded, either because most questions were not unanswered or because the answers contained obvious inconsistencies. The remaining 294 questionnaires yielded a response rate of 65.6 percent (64.7 percent for version 1, transfer situation; 66.5 percent for version 2, no-transfer situation). One-hundred-three of the 127 firms included in the sample were represented by the returned questionnaires. To test whether the employees who received and returned version 1 of the questionnaire were significantly different from those who received and returned version 2 , the two groups were compared in regard to demographic and firm-specific characteristics. No significant difference could be detected.

Due to the specific design of the questionnaire, not all respondents had to answer the part that refers to the employee's most recent information transfer decision. Fourtyfour respondents could not answer this part because they had not been asked for information during the year before the survey; 43 of the respondents who received a questionnaire that inquired about a rejection of an information request indicated that they had not rejected any requests; 3 of the employees who were asked to describe a transfer situation indicated that they had rejected all information inquiries by colleagues 
from other firms. Altogether the survey yielded 204 characterizations of information requests, of which 119 referred to transfer situations and 85 to no-transfer situations.

\subsection{Determining underlying factors}

Several variables measured by the questionnaire correlate strongly, opening up the possibility of reducing the number of variables and detecting underlying dimensions by factor analysis of the data. Two principal component analyses based on correlation matrices were computed for this purpose, one analyzing the variables describing the context of the transfer decision; the other, the variables describing the requested information. (The number of factors extracted was determined by the Kaiser criterion (Eigenvalue $>1$ ) and varimax rotation was used.)

Context-related factors: The factor analysis of the context variables results in four factors accounting for 67.2 percent of the total variance (table 2 ). The factor loadings are distinct and can be interpreted meaningfully. 
Table 2: Factor loadings for the variables describing the context of a transfer decision

\begin{tabular}{|c|c|c|c|c|}
\hline & $\begin{array}{l}\text { Instrumentality } \\
\text { of relationship/ } \\
\text { friendship }\end{array}$ & $\begin{array}{c}\text { Similarity } \\
\text { of market } \\
\text { segment }\end{array}$ & $\begin{array}{l}\text { Technological } \\
\text { knowledge of } \\
\text { inquiring party }\end{array}$ & $\begin{array}{l}\text { Similarity } \\
\text { of } \\
\text { technology }\end{array}$ \\
\hline Variable & Factor 1 & Factor 2 & Factor 3 & Factor 4 \\
\hline \multicolumn{5}{|l|}{$\begin{array}{l}\text { Usefulness of previous } \\
\text { exchanges with inquirer to ... }\end{array}$} \\
\hline - employee & 0.79 & 0.08 & 0.17 & -0.19 \\
\hline - employee's firm & $\underline{0.76}$ & 0.03 & 0.37 & -0.02 \\
\hline - inquirer & 0.86 & -0.02 & -0.13 & -0.09 \\
\hline - inquirer's firm & 0.79 & -0.08 & 0.09 & 0.10 \\
\hline Friendship & 0.73 & -0.07 & 0.30 & -0.05 \\
\hline Duration of relationship & $\underline{0.54}$ & 0.03 & 0.08 & 0.21 \\
\hline $\begin{array}{l}\text { General cooperativeness } \\
\text { of inquirer }\end{array}$ & $\underline{0.52}$ & .0 .16 & 0.49 & -0.12 \\
\hline Similarity of regional market & -0.01 & 0.92 & 0.04 & 0.07 \\
\hline Similarity of customer group & -0.06 & 0.89 & -0.01 & 0.29 \\
\hline $\begin{array}{l}\text { Technological leadership of } \\
\text { inquirer's firm }\end{array}$ & 0.10 & 0.11 & $\underline{0.82}$ & 0.00 \\
\hline Success of inquirer's firm & 0.04 & -0.11 & $\underline{0.79}$ & 0.25 \\
\hline Inquirer's technological expertise & 0.34 & 0.10 & $\underline{0.62}$ & -0.12 \\
\hline Similarity of production technology & 0.00 & 0.06 & 0.08 & 2.86 \\
\hline Product similarity & -0.02 & 0.35 & -0.02 & 0.75 \\
\hline
\end{tabular}

The variables that load with more than 0.5 on the first factor describe aspects of the relationship between the information owner and the person asking for information. This factor takes on a high value if the two parties have exchanged useful information in the past, information useful for both the individuals and the firms. Closely connected to the occurrence of such exchanges are three other variables: (1) the degree to which the information owner characterizes the information seeker as a friend, (2) the duration of their relationship, and (3) the information owner's assessment of the information seeker's cooperativeness. Taking these variables together, this factor can be interpreted 
as describing both the instrumentality of the relationship between information owner and information seeker - and, closely connected to this concept, the friendship between the two individuals.

The second factor is characterized by variables that describe the extent to which the two firms sell their products in the same regionally defined markets and to the same customer groups. Accordingly, this factor is named similarity of the market segment.

The third factor, labeled technological knowledge of inquiring party takes on a large value if the information owner perceives the firm of the inquirer as one of the technological leaders in the industry and as successful, and if he or she attributes to the inquirer a large degree of technological expertise.

The fourth factor describes primarily the extent to which the two firms employ comparable production and product technologies, and thus the name similarity of technology.

None of the variables that characterize the context of the transfer decision relates directly to the degree of competition between the two firms. The degree of competition is operationalized by combining two variables. It is assumed that firms that sell similar products to the same customer group are likely to be direct competitors, whereas firms that sell different products to different customer groups are not direct competitors. Thus the corresponding variables from factor 2 and factor 4 can be used to calculate an indicator for the degree of competition. ${ }^{4}$ Employees were not asked directly whether the inquirer's firm was a direct competitor since the pretest of the questionnaire had shown that this would have decreased the acceptance of the questionnaire to a considerable extent, possibly due to employees' perceptions of socially desirable behavior.

4 The square root of the product of the variables was used. The square root was taken so that the indicator has the same 1-to-7 value range as all other variables 
Information-related Factors: A second factor analysis combines the variables describing the information content into four linear independent factors (table 3). These four factors account for 65.6 percent of the total variance. Again, the factor loadings are distinct and can be explained meaningfully.

Table 3: Factor loadings for the variables describing the requested information

\begin{tabular}{|c|c|c|c|c|}
\hline & $\begin{array}{l}\text { Importance of } \\
\text { information to } \\
\text { deciding party }\end{array}$ & $\begin{array}{l}\text { Importance of } \\
\text { information to } \\
\text { inquiring party }\end{array}$ & $\begin{array}{l}\text { Degree to which in- } \\
\text { formation relates to } \\
\text { domains of low com- } \\
\text { petitive importance }\end{array}$ & $\begin{array}{c}\text { Availability } \\
\text { of alternative } \\
\text { information } \\
\text { sources }\end{array}$ \\
\hline Variable & Factor 1 & Factor 2 & Factor 3 & Factor 4 \\
\hline \multicolumn{5}{|l|}{ Importance of information $10 . .}$. \\
\hline - employee's firm & 0.76 & 0.20 & 0.04 & -0.17 \\
\hline - employee & $\underline{0.71}$ & 0.13 & 0.15 & -0.17 \\
\hline - inquirer's firm & 0.18 & 0.90 & 0.04 & -0.04 \\
\hline - inquirer & 0.20 & $\underline{0.90}$ & 0.07 & 0.01 \\
\hline \multicolumn{5}{|l|}{$\begin{array}{l}\text { Degree to which information } \\
\text { relates to ... }\end{array}$} \\
\hline - product quality & 0.75 & 0.14 & -0.06 & 0.11 \\
\hline - cost savings & $\underline{0.51}$ & 0.03 & 0.48 & 0.02 \\
\hline - maintenance & -0.03 & -0.02 & $\underline{0.85}$ & 0.05 \\
\hline $\begin{array}{l}\text { - environmental and safety } \\
\text { regulations }\end{array}$ & -0.12 & -0.01 & $\underline{0.78}$ & 0.05 \\
\hline - operations & 0.43 & 0.08 & 0.59 & -0.03 \\
\hline $\begin{array}{l}\text { - simplification of employee's } \\
\text { job }\end{array}$ & 0.36 & 0.18 & $\underline{0.58}$ & 0.04 \\
\hline $\begin{array}{l}\text { Likelihood that inquirer could } \\
\text { develop similar solution }\end{array}$ & 0.00 & -0.06 & -0.06 & 0.86 \\
\hline $\begin{array}{l}\text { Availability of other external } \\
\text { information sources to inquirer }\end{array}$ & -0.14 & 0.04 & 0.17 & $\underline{0.82}$ \\
\hline
\end{tabular}

The first information-related factor describes the employee's perception of the requested information's importance to him- or herself and to the firm. It is named 
importance to the deciding party. Note that the factor analysis allocates to this factor the variable that reflects the degree to which the information allows improvements in quality. (The variable loads with 0.75 on this factor.) A similar strong loading cannot be reported for the variable that describes the degree to which the requested information relates to cost savings. This variable loads nearly equally strong on the first factor (0.51) and the third (0.48). It was argued earlier that quality-related information in this specific industry is especially important to a firm's relative competitiveness; this argument is supported by the data.

The second factor, importance of information to the inquiring party, is characterized by two variables that reflect the importance the information owner believes the information to have for the information inquirer and his or her firm. Note that this factor is statistically independent from the one that characterizes the importance of the information to the deciding party. Apparently, managers differentiate between the value that a specific unit of information possesses for themselves and the value it creates for others.

The third factor, degree to which information relates to domains of low competitive importance, is primarily characterized by four variables. These variables indicate the degree to which the information helps to improve maintenance, to fulfill environmental and safety regulations, to simplify the production process or the tasks of the employee who is asked for information, and, to some extent, to reduce production costs. A high value on this factor implies that the information relates to domains that may be important for a firm's overall performance but that are not domains in which the firms, at least in the investigated industry, compete fiercely with each other (again, an exception is radical cost savings).

The fourth and last factor, availability of alternative information sources, reflects whether the information owner thinks that alternatives are open to the inquirer to cover his or her informational needs. Such alternatives include developing similar 
information internally or acquiring comparable information from other external sources.

In addition to these factors and the indicator for competition, the following analysis includes one further variable. As discussed, information transfers are expected to be part of reciprocal relationships. Therefore the surveyed employees were asked to indicate to what extent they expected their transfer decision to change the inquirer's willingness to provide information to them in the future - that is, the extent to which they expected their specific information transfer decision to increase their chance of receiving information (or, if they had refused to provide the requested information, the extent to which they expected the transfer to decrease their chance of receiving information).

\subsection{Probit analysis for contrasting transfer versus no-transfer decisions}

Probit analysis was used to contrast circumstances under which employees were willing to provide requested information with those under which no informal information transfer took place. The probit analysis included as independent variables all factors described earlier (except the two factors that jointly constitute the indicator for the degree of competition), as well as the indicator for the degree of competition and the measure of the expected change in the inquirer's willingness to reciprocate information. To compare the relative influence of the factors, all variables were transformed into zscores.

The eight independent variables were combined into a single probit model (Amemiya 1979). The vector $\beta$ of the eight parameter estimates $\beta_{i}, i=1, . ., 8$ was derived to maximize the $\log$ likelihood function $L$, with $Y_{i}$ equal to 1 when the requested information was transferred and $Y_{\mathrm{i}}$ equal to 0 when the information was not transferred. $X_{i}$ is the vector of values of the independent variables for the $i$-th case, and $\Phi\left(X^{\prime}{ }_{i} \beta\right)$ represents the probit function. 


$$
L=\sum_{i=1}^{n}\left[Y_{i} \ln \Phi\left(X^{\prime}{ }_{i} \beta\right)\right]+\sum_{i=1}^{n}\left(1-Y_{i}\right) \ln \left[1-\Phi\left(X^{\prime} i \beta\right)\right]
$$

Probit analysis requires cases without missing values. For most questions, the questionnaire offered "do not know" as a possible reply. The pretest had suggested that this option would improve validity. At the same time, it led to a considerable number of missing values; 21 descriptions of transfer situations and 38 of no-transfer situations contain at least one missing value. In 36 of the cases with missing values, the respondents had answered all but one or two questions. For these cases, an estimate of the missing values was calculated using the regression approach described in Griliches (1986, pp. 1488-1490). For each variable with missing values, the original data were divided into two subsamples, one containing the cases with missing observations and the other containing those with complete observations. Using the latter subsample, the coefficients of a linear regression model with the missing variable as the dependent variable were estimated. These estimated coefficients were then used to compute estimates for each missing value. This approach assumes that the estimated regression coefficients are constant across the subsamples. By calculating estimates for the cases with one or two missing values, the number of cases that can be considered in the probit analysis increases from 147 to 183.

Table 4 reports estimated parameters for the probit model, both for the original data set and for the data set including substitutes for missing values.

\section{Results}

It was proposed that managers do not leak information randomly, but rather trade information consciously. In section 3, the hypothesis was put forward that a manager's information-transfer decision is strongly influenced by the perceived costs 
and benefits that a transfer creates for his or her firm - costs through reducing the rent that the firm can expect to draw from the innovation, and benefits through increasing the chance of receiving valuable information in return. As shown in the following subsection, the data strongly support this proposition.

\subsection{Information Trading}

The estimated probit coefficients (table 4) provide substantial evidence for the general hypothesis that technical employees trade information. The surveyed employees appear to exchange information in such a way that a transfer creates little costs but potentially high benefits for the firms involved. Information is provided in the expectation that this will significantly increase the likelihood of receiving valuable information in return. The expected change in the inquirer's willingness to provide information, as well as the technological knowledge of the inquiring party, discriminate strongly and positively between transfer and no-transfer situations. At the same time, employees also take the variables influencing the costs of transferring information into account. 
Table 4: Probit coefficients in equation to explain decision whether or not to provide requested information to a colleague from another firm

\begin{tabular}{|c|c|c|}
\hline Independent Variable/Factor & $\begin{array}{l}\text { Probit coefficients for } \\
\text { original data set } \\
\text { (standard deviation) } \\
n=147\end{array}$ & $\begin{array}{c}\text { Probit coefficients for data } \\
\text { set including estimates of } \\
\text { missing values } \\
\text { (standard deviation) } \\
n=183\end{array}$ \\
\hline Intensity of competition & $\begin{array}{l}-0.638 * * \\
(0.249)\end{array}$ & $\begin{array}{l}-0.432 * * \\
(0.164)\end{array}$ \\
\hline $\begin{array}{l}\text { Availability of alternative information } \\
\text { sources }\end{array}$ & $\begin{array}{l}0.488^{* *} \\
(0.207)\end{array}$ & $\begin{array}{l}0.476^{* *} \\
(0.168)\end{array}$ \\
\hline Importance of information to deciding party & $\begin{array}{l}-0.564 * \\
(0.257)\end{array}$ & $\begin{array}{l}-0.392 * \\
(0.169)\end{array}$ \\
\hline $\begin{array}{l}\text { Degree to which information relates to } \\
\text { domains of low competitive imporance }\end{array}$ & $\begin{array}{r}0.231 \\
(0.227)\end{array}$ & $\begin{array}{l}0.294 * \\
(0.172)\end{array}$ \\
\hline $\begin{array}{l}\text { Expected change of inquirer's willingness to } \\
\text { provide information }\end{array}$ & $\begin{array}{l}2.9011^{* * *} \\
(0.702)\end{array}$ & $\begin{array}{l}2.909 * * * \\
(0.670)\end{array}$ \\
\hline Importance of information to inquiring pary & $\begin{array}{r}0.095 \\
(0.234)\end{array}$ & $\begin{array}{r}0.018 \\
(0.164)\end{array}$ \\
\hline Technological knowledge of inquiring party & $\begin{array}{l}0.614^{* *} \\
(0.237)\end{array}$ & $\begin{array}{l}0.306^{*} \\
(0.167)\end{array}$ \\
\hline Instrumentality of relationship / friendship & $\begin{array}{r}0.274 \\
(0.248)\end{array}$ & $\begin{array}{r}0.275 \\
(0.179)\end{array}$ \\
\hline Intercept & $\begin{array}{l}1.526^{* * *} \\
(0.408)\end{array}$ & $\begin{array}{l}1.324 * * * \\
(0.374)\end{array}$ \\
\hline$\chi^{2}-$ Statistic & $134.865 * * *$ & $161.294 * * *$ \\
\hline
\end{tabular}

Interpretation: A positive probit coefficient indicates that requested information is more likely provided if the variable takes on a positive value.

The reported significance values are for one-sided $t$-tests.

*** indicates significance beyond the 0.001 level,

* * indicates significance beyond the 0.01 level,

* indicates significance beyond the 0.05 level.

Cost of trading information: In section 3.1, it was argued that transferring information creates high costs for the transferring firm if the information is provided to a competitor, if it relates to a dimension on which the involved firms compete, and if 
no other sources for the same or similar information are available to the inquirer.

Under such circumstances, transferring information leads to a considerable competitive backlash. If the hypothesis that employees trade information within the economic interest of their firms is correct, then employees should be less inclined (ceteris paribus) to exchange information in situations in which transferring information is likely to generate considerable economic costs.

This hypothesis is supported by the probit analysis. The likelihood of an information transfer significantly decreases if the firms are direct competitors, if the information is not easily available from alternative information sources, and if the information is of high importance to the firm of the employee who is making the transfer decision. Also, if information relates to domains of low competitive importance, then apparently it is more likely to be transferred. The coefficient for the last factor, however, is significant only if the larger data set, including estimates of missing values, is used.

The intensity of competition between the involved firms is one of the variables that discriminate strongly between providing and not providing information. Nevertheless, in 29.4 percent of the situations in which information was transferred, the information-receiving firm and the information-providing firm are likely to be competitors. 5 Keep in mind that handing information to a competitor does not necessarily harm the information-providing firm. For example, if information does not relate to a domain in which the firms compete or if the inquirer easily can obtain similar information from another source, then transferring this information - even to a competitor - does not put the transferring firm at a disadvantage. The results show that employees decide accordingly.

5 In these situations, the indicator of competition, ranging from 1 to 7 , is equal to or larger than 5 . That is, the firms sell similar products to the same customer group. 
Whereas competition and the importance of the information to the transferring party have a negative impact on the likelihood that information is transferred, the availability of alternative information sources and the degree to which information relates to areas of low competitive importance positively influence the probability that requested information will be transferred. To put it differently, if an employee believes that the inquirer could acquire without great effort the same or similar information from some other source or if the specific information is not important for the firms' competitive position relative to each other, then the employee is more inclined to provide the requested information. Under such circumstances, transferring information, even to a competitor, can be expected not to reduce the rent that the firm can reap from the information, or to reduce it only slightly.

To sum up, the data support the hypothesis that the decision whether to provide requested information is strongly influenced by the economic costs for the transferring firm. Information transfer is more likely to occur the less the transfer reduces the rent that the transferring firm is expected to derive from the information. The factors relating to this hypothesis (degree of competition, importance of the information to the deciding party, degree to which the information relates to an area of low competitive importance, and availability of alternative information sources) distinguish significantly between transfer and no-transfer situations.

Benefit of trading information: In section 3.2, it was proposed that informal information transfer creates not only costs, but also economic benefits for the transferring firm, benefits in the form of receiving valuable information in return. Information trading yields a net gain for the firm if the benefits outweigh the costs. The probit analysis (table 4) strongly supports the proposition that information is provided in circumstances in which it is expected that considerable benefits for the providing firm will be generated. 
Transferring information considerably increases the provider's chance to obtain information from the receiver. The variable "expected change of inquirer's willingness to provide information" discriminates most strongly between transfer and no-transfer situations (table 4). In 72.6 percent of the transfer cases, employees assumed that providing information would improve their chance of receiving information from the inquirer. In 32 percent of the no-transfer situations, they expected that the refusal to transfer would reduce their chance to receive information. It is important to note that the expected change, not the overall magnitude of the inquirer's willingness to provide information, was measured. ${ }^{6}$ It is the incremental change in the likelihood to receive information that influences benefits from information trading.

It has been hypothesized that, because the receiver's obligation to reciprocate is expected to increase with the value received, information is more likely to be exchanged if it is of high importance to the information-receiving party. The probit analysis, however, does not detect a direct effect of the importance of the information for the receiving party on the transfer decision. For both data sets, the respective coefficient is not significant. A significant relationship between the importance of the information to the receiving party and the expected change of the receiver's willingness to provide information in the future, however, can be reported. Employees who transferred information that they considered important to the inquiring party 7 expected more often that this would considerably improve their chance of receiving information than did employees who transferred information the considered to be low importance to the receiver (table 5).

6 The following question was used to measure this variable: "Did you expect that giving [not giving] him this particular piece of information would change your chances of receiving helpful information from him in the future?" A 7 - point scale was used, with 1 identified as "much less likely to receive," 4 as "no change," and 7 as "much more likely to receive."

7 Information is classified as being of low importance to the receiving party if the value of the relating factor is less than the median. A value equal to or above the median serves as an indicator for high importance. 
Table 5: Importance of the transferred information and expected change of the inquirer's willingness to reciprocate. Percentage of cases per group.

\begin{tabular}{|c|c|c|c|c|c|}
\hline \multirow{3}{*}{$\begin{array}{l}\text { Importance of transferred } \\
\text { information to inquiring party }\end{array}$} & \multicolumn{5}{|c|}{$\begin{array}{c}\text { Expected change of inquirer's willingness } \\
\text { to provide information }\end{array}$} \\
\hline & \multicolumn{2}{|l|}{ No change } & \multicolumn{3}{|c|}{$\begin{array}{l}\text { Much more likely to } \\
\text { provide information }\end{array}$} \\
\hline & 4 & 5 & $6^{\circ}$ & 7 & $\Sigma$ \\
\hline - Low & $31.0 \%$ & $20.7 \%$ & $27.6 \%$ & $20.7 \%$ & $\begin{array}{l}100 \% \\
(\mathrm{n}=58)\end{array}$ \\
\hline - High & $25.4 \%$ & $5.1 \%$ & $39.0 \%$ & $30.5 \%$ & $\begin{array}{l}100 \% \\
(n=59)\end{array}$ \\
\hline
\end{tabular}

Chi-square $=8.121 ; \mathrm{p}<0.05$

Note: The data are from the 119 descriptions of transfer situations. Two of these cases had to be eliminated due to missing values.

Apparently, employees expect that an information receiver's cooperativeness (i.e. his or her willingness to provide information) increases more if he receives information of high value than if he receives some of low value. Note, however, that this relationship does not always hold true. In nearly one-third of the cases in which the transferred information was considered important, the surveyed employee did not expect this transfer to change the cooperativeness of the inquiring party. How can this be explained? These employees may have exchanged information extensively in the past; the transfers described by them may have reinforced but not changed existing relationships. This explanation is supported by the data. Relationships that have existed for an extended period of time are less affected by a single transfer decision than are newer relationships. The correlation between the expected change of the information receiver's willingness to provide information and the length of the relationship is 
$\mathrm{r}=-0.24, \mathrm{p}<0.01$. Relationships develop over time, becoming more and more independent of single transfer decisions.

Even if the inquirer is eager to reciprocate, his or her cooperativeness remains without economic value if no relevant information exists that could be returned. Therefore, as hypothesized in section 3.2, employees should be more inclined to exchange information with a colleague whose firm controls a state-of-the-art know-how pool and who is knowledgeable him- or herself, than with someone who is barely keeping up with technological change. This hypothesis is strongly supported by the data. The probability of an information exchange increases significantly if the inquiring party is known to control considerable technical knowledge (table 4).

In summary, the data provide strong evidence for the hypothesis that information is traded with the expectation of receiving economically valuable information in return. Information is transferred when it is expected that doing so creates an economic benefit for the transferring firm.

\subsection{The impact of friendship}

In the pilot research, several interviewees reported that they considered most of their transfer partners to be good acquaintances or even friends. Often they had known each other for several years and had exchanged information in the past. Several studies have demonstrated the importance of friendship and personal trust for the disclosure of information (Sitkin 1986, Berg and Clark 1986, Miell and Duck 1986). These studies, however, do not discuss whether friendship fosters information transfer because it encourages asking for information or because it encourages providing information.

The factor analysis yielded one factor that describes the personal relationship between inquirer and information owner and that characterizes their information transfer history: the factor instrumentality of the relationship/friendship. The probit analysis detects no significant impact of this factor on the probability that a specific 
information is transferred (table 4). Apparently, in making the decision whether to provide requested information, whether the inquirer is a friend is of secondary importance. This finding does not necessarily contradict other studies that have found friendship to be an important characteristic of information-transfer networks.

Friendship may define the network within which information is exchanged. Gross and McMullen (1982), for example, argue that asking a friend for help creates fewer psychological costs than asking a stranger. Once the network is established and once a person has created the need for a transfer decision by asking a colleague for information, however, friendship has little impact on the transfer decision.

\subsection{Information trading and firm performance}

The data presented so far support the notion that employees trade technical information within the economic interests of their firms - as they perceive it - and that friendship plays a secondary role for the decision whether to transfer a specific information. The question that must now be addressed is whether informal information trading creates an observable benefit for the firms.

The managers surveyed were asked to indicate the general propensity of their firms to participate in the informal exchange of technical information. In addition, they were asked to rate the economic success of their firms in comparison to the industry average by using a 7-point scale, with 1 meaning "well below average" and 7 "well above average" economic performance. ${ }^{8}$

The data suggest a connection between the inclination of a firm to participate in informal information transfers and its economic performance. The degree to which a

8 This performance measure was used because several of the firms surveyed do not publicize financial information. Because in 244 of the 294 cases, at least two respondents belonged to the same firm, the reliability of the performance measure can be determined through an analysis of variance with firm success as a dependent variable and firm as the independent variable. The resulting coefficient of determination $r^{2}$ equals $0.59(p<0.001)$.) 
firm's employees participate in the informal information exchange correlates positively $(r=0.19, p<0.001)$ with the firm's economic success as evaluated by the surveyed employee.

Managers who worked for firms that did not participate in the informal information exchange indicated, on average, a significantly lower economic performance for their firms (mean=4.7) than did managers whose firms actively participated in this kind of information transfer (mean=5.8, significance of mean difference: $p<0.001$; table 6).

Table 6: Average perceived economic success contingent on participation of firm in informal information exchange

\begin{tabular}{lcc}
\hline $\begin{array}{l}\text { Participation in informal } \\
\text { information transfer between } \\
\text { firms }\end{array}$ & $\begin{array}{c}\text { Economic } \\
\text { success } \\
\text { (mean) }\end{array}$ & $\begin{array}{c}\text { Number of } \\
\text { respondents }\end{array}$ \\
\hline 1 (no participation) & 4.68 & 16 \\
2 & 4.93 & 30 \\
3 & 5.25 & 39 \\
4 & 5.71 & 68 \\
5 & 5.26 & 55 \\
6 & 5.77 & 48 \\
7 (active participation) & 5.82 & 27 \\
\hline
\end{tabular}

In summary, the survey offers suggestive evidence for a positive link between the economic performance of a firm and the participation of its employees in informal information trading. It should be noted that the survey itself cannot determine cause and effect. Since employees' information-exchange behavior appears to be oriented 
toward their firms' benefit, however, it can be postulated that participation in informal information transfer drives economic performance of these firms.

\section{Discussion}

The observed decisions reveal information-transfer patterns that strongly support the hypothesis that employees trade information and that information trading is desirable from a firm's point of view. Employees are less inclined to provide a specific piece of information if doing so is likely to considerably hurt their firm's ability to capture economic rents from the information; they are more willing to provide information if they can expect to receive valuable information in return. Factors like friendship or duration of the relationship with the inquirer appear to be of secondary importance for the decision whether to provide a specific unit of information. (Such factors, however, may be significant for defining the network of personal contacts within which information is exchanged.) In addition, the evidence suggests a positive link between informal information trading and a firm's economic performance.

One important limitation of this study must be pointed out. All empirical data are drawn from one industry, the U.S. specialty steel and mini-mill industry. It remains untested whether the close alignment of managers' and firms' interests that apparently exists in the steel industry also can be found in other industries. Different information trading patterns may be expected in those industries characterized by high job mobility and difficulties linking employees' contributions to the performance of their firms (Rogers 1982). A pilot study in the aerospace industry, however, suggests that, even in such an industry, information-trading patterns similar to those found in the steel industry can be observed (Gavrilis 1989). 
Several interviewees pointed out that the inclination to cooperate and to participate in informal information trading has increased considerably with the entrance of new competitors, whether foreign competitors or domestic ones coming from outside the traditional boundaries of the industry. How can this be explained? Information trading is risky. The pay-off of a cooperative action is uncertain. For the most part, providing and receiving information do not occur concurrently, and the costs and benefits can be evaluated precisely only after the exchange has occurred. Several studies have shown that individuals, if deciding under uncertainty, tend to weigh potential losses heavier than potential gains (Kahneman, Slovic, and Tversky 1982). This conservative behavioral tendency certainly impedes the emergence of information trading. The advent of new competition from sectors outside the traditional boundaries of the industry, however, increases the benefits of trading and the costs of not cooperating. Several managers interviewed in this study argued that foreign competition forces them to innovate constantly in order to remain competitive. Under such circumstances, they asserted, firms cannot afford not to cooperate; they must use available know-how efficiently. Informal information trading can contribute to this goal.

Many circumstances are conceivable under which an information exchange is in the economic interest of the involved firms, yet under which formal transfer mechanisms are ruled out because they are too expensive. Most formal informationtransfer agreements are complex legal constructs that attempt to address problems stemming from opportunistic behavior and asymmetric information. The resulting high transaction costs are one reason why only a few firms use some formalized technology transfer process and why only a small fraction of available information is transferred this way (Grefermann and Röthlingshöfer 1974; Reid and Reid 1987) Unlike formal information transfer, the informal transfer entails limited transaction costs. In particular, contracting costs and control and enforcement costs are 
insignificant in comparison to the formal transfer: No lengthy negotiations are required, no costly legal institutions are necessary to monitor the information exchange. These simplifications are made possible at the expense of legal mechanisms that could be used to force the trading party into fulfilling its obligations. Fortunately, other, less costly control mechanisms do exist. For example, news about uncooperative behavior of a player appears to travel fast within the surveyed industry. Thus, by not cooperating in one relationship, a player puts several relationships in jeopardy - a strong mechanism for enforcing cooperation.

Information leading to small, incremental improvements is especially likely to fall into the category of information not suitable for formal transfer agreements. Firms that do not use informal information trading for acquiring this kind of information, then, are sacrificing an important information source. Several empirical investigations have shown that incremental improvements can be very important to a firm's economic success (Enos 1962, Hollander 1965, Gold 1979).

The notion of information trading challenges some aspects of our traditional beliefs regarding the desirable permeability of firm boundaries. It is a widely shared view that firms have to seal or at least control their boundaries to prevent information leakage. Measures are advocated that restrain employees from transferring information informally across organizational boundaries (e.g. Hamel, Doz, and Prahalad 1989). Firms that make their boundaries impenetrable to informal information transfer, however, may prevent not only leakage of information, but also its acquisition.

Opening a firm's boundaries to allow information trading can create economic benefits, though entailing the risk that employees exchange information against the firm's interests. As shown here, information trading is not always desirable. It is advantageous if employees are aware of when to exchange and when to hide information and if they act accordingly. Conceivably, several mechanisms can be employed to induce desirable information-trading behavior. A fine-grained rule system 
is one possibility. Such a system, however, is likely to be inflexible, difficult to keep updated, and potentially demotivating. In the context of this study, no firm was encountered that had established such a system. Another possibility is to (1) provide employees with an incentive scheme that motivates them to act in the interests of the firm and (2) enable them to make well-informed decisions. A need to improve ongoing practices in the management of technically oriented employees appears necessary, especially with regard to the second point. Data from West Germany show that middlelevel managers who are responsible for technical aspects (e.g. R\&D managers), believe that they are not well-informed about their firm's goals and strategies (Pritzl 1987). This entails the possibility that due to insufficient managerial information, some technical information is traded against a firm's interests, even if the individual manager intends differently.

Information trading creates incentives to innovate. Internally generated technical knowledge is used not only within a firm, but also bartered for further knowledge - as long as the benefits outweigh the costs. A firm that does not keep up with technical change loses its attractiveness as a trading partner. Thus reducing internal technology development at the same time inhibits the ability of a firm to acquire information externally. Internal technology development and information trading are not substitutes, but rather complements. 


\section{REFERENCES}

Adams, J. Stacy. 1965. "Inequity in Social Exchange." In Advances in Experimental Social Psychology, edited by Leonard Berkowitz, pp. 267-299. New York: Academic Press.

Allen, Thomas J. 1984. Managing the Flow of Technology: Technology Transfer and the Dissemination of Technological Information within the R\&D Organization. Cambridge, Mass.: M.I.T. Press.

Amemiya, T. "Qualitative Response Models: A Survey." Iournal of Economic Literature, 18: 1483-1536.

Barnett, Donald F., and Robert W. Crandall. 1986. Up from the Ashes: The Rise of the Steel Minimill in the United States. Washington, D.C.: Brookings Institution.

Berg, John H., and Margaret S. Clark. 1986. "Differences in Social Exchange Between Intimate and Other Relationships: Gradually Evolving or Quickly Apparent?." In Friendship and Social Interaction, edited by Valerian J. Derlega and Barbara Winstead, pp. 101-128. New York: Springer.

Blau, Peter M. 1964. Exchange and Power in Social Life. New York: Wiley.

Bradbury, Frank, Paul Jervis, Ron Johnston, and Alan Pearson. 1978. Transfer Processes in Technical Change. Alphen aan den Rijn, The Netherlands: Sijthoff \& Noordhoff.

Carter, Anne P. 1989. "Knowhow trading as economic exchange." Research Policy 18: 155-163.

Clark, Margaret S. 1985. "Implications of Relationship Type for Understanding Compatibility." In Compatible and Incompatible Relationships, edited by William Ickes, pp. 119-140. New York: Springer.

Czepiel, John A. 1974. "Word-of-Mouth Processes in the Diffusion of a Major Technological Innovation." Journal of Marketing Research 11: 172-180.

Emerson, Richard M. 1976. "Social Exchange Theory." Annual Review of Sociology 2: 35-362.

Enos, J. L. 1962. Petroleum Progress and Profits: A History of Process Innovation. Cambridge, Mass.: M.I.T. Press.

Gavrilis, Theofanis. 1989. Information Trading in the Aerospace Industry. Master's Thesis, Sloan School, Massachusetts Institute of Technology.

Gold, Bella. 1979. Productivity, Technology and Capital: Economic Analysis, Managerial Strategies, and Government Policies. Lexington, Mass.: Lexington.

Grefermann, Klaus, and Karl. Ch. Röthlingshöfer. 1974. Patentwesen und technischer Fortschritt, Teil II: Patent- und Lizenzpolitik der Unternehmen. Göttingen. 
Griliches, Zvi. 1986. "Economic Data Issues." In Handbook of Econometrics, Volume III, edited by Zvi Griliches and Michael D. Intriligator, pp. 1465-1514. Amsterdam: NorthHolland.

Gross, Alan E., and Peg A. McMullen. 1982. "The Help-Seeking Process." In Cooperation and Helping Behavior, edited by Valerian J. Derlega and Janusz Grezlak, pp. 305-326. New York: Academic Press.

Hamel, Gary, Yves L. Doz, , and C. K. Prahalad. 1989. "Collaborate with Your Competitors - and Win." Harvard Business Review 67: 133-139.

Hollander, Samuel. 1965. The Sources of Increased Efficiency: A Study of Du Pont Rayon Plants. Cambridge, Mass.: M.I.T. Press.

Kahneman, Daniel, Paul Slovic, and Amos Tversky (Eds.), 1982. Iudgement under Uncertainty: Heuristics and Biases. Cambridge, England: Cambridge University Press.

Katz, Ralph, and Michael L. Tushman. 1981. "An Investigation into the Managerial Roles and Career Paths of Gatekeepers and Project Supervisors in a Major R\&D Facility." R\&D Management, 11: 103-110.

Levin, Richard C.; Alvin K. Klevorick; Richard R. Nelson, and Sidney G. Winter. 1987. "Appropriating the Returns from Industrial Research and Development." Brookings Papers on Economic Activity No. 3: 783-820.

Levine, Sol, and Paul E. White. 1961. "Exchange as a Conceptual Framework for the Study of Interorganizational Relationships." Administrative Science Quarterly 5: 583601.

Macaulay, Stewart. 1963. "Non-Contractual Relations in Business: A Preliminary Study." American Sociological Review 14: 55-69.

Mansfield, Edwin. 1985. "How Rapidly Does New Industrial Technology Leak Out?." The Journal of Industrial Economics 34: 217-223.

Martilla, John A. 1971. "Word-of-Mouth Communication in the Industrial Adoption Process." Lournal of Marketing Research 8: 173-178.

Miell, Dorothy, and Steve Duck. 1986. "Strategies in Developing Friendships." In Friendship and Social Interaction, edited by Valerian J. Derlega and Barbara Winstead, pp. 129-143. New York: Springer.

Miller, Lynn C., and John H. Berg. 1984. "Selectivity and Urgency in Interpersonal Exchange."In Communication, Intimacy, and Close Relationships, edited by Valerian J. Derlega pp. 161-205. Orlando, Fla.: Academic Press.

Mills, Judson, and Margaret S. Clark. 1982. "Exchange and Communal Relationships. In Review of Personality and Social Psychology Vol. 3, edited by Ladd Wheeler, pp. 121144. Beverly Hills, Calif.: Sage. 
Perlman, Daniel, and Beverley Fehr. 1986. "Theories of Friendship: The Analysis of Interpersonal Attraction." In Friendship and Social Interaction, edited by Valerian J. Derlega and Barbara Winstead, pp. 9-40. New York: Springer.

Porter, Michael E. 1983. "The Technological Dimension of Competitive Strategy." In Research on Technological Innovation, Management and Policy, Vol. 1, edited by Richard S. Rosenbloom, pp. 1-33. Greenwich, Conn.: Jai Press.

Porter, Michael E. 1985. Competitive Advantage: Creating and Sustaining Superior Performance. New York: Free Press.

Pritzl, Magdalena, 1987, Die Bedeutung der Zielklarheit für die Führungskräfte des Unternehmens: Eine empirische Analyse. München: GBI.

Reid, S. D., and L. J. Reid. 1987. "Promoting Technology Transfer: A Public Policy Perspective." In Innovation: Adaptation and Growth, edited by Roy Rothwell and John Bessant, pp. 93-102. Amsterdam: Elsevier Science.

Rogers, Everett M. 1982. "Information Exchange and Technological Innovation." In The Transfer and Utilization of Technical Knowledge, edited by Devendra Sahal, pp. 105-123. Lexington, Mass.: Lexington Books.

Saxenian, Annalee. 1985. "The Genesis of Silicon Valley." In Silicon Landscapes, edited by Peter Hall and Ann Markusen, pp. 20-34. Boston: Allen \& Unwin.

Schrader, Stephan. 1990. Zwischenbetrieblicher Informationstransfer: Eine empirische Analyse kooperativen Verhaltens. Berlin: Duncker \& Humblot.

Sitkin, Sim B. 1986. Selective Exposure: Determinants of Secrecy Behavior Among Engineers in Three Silicon Valley Semiconductor Firms. University of Texas at Austin: Photocopy.

Teece, David J. 1986. "Profiting from Technological Innovation: Implications for Integration, Collaboration, Licensing and Public Policy." Research Policy 15: 285-305.

Walster, Elaine, Ellen Berscheid, and G. William Walster. 1976. "New Directions in Equity Research." In Advances in Experimental Social Psychology, Volume 9: Equity Theory Towards a General Theory of Social Interaction, edited by Leonard Berkowitz and Elaine Walster, pp. 1-42. New York: Academic Press.

von Hippel, Eric. 1987. "Cooperation Between Rivals: Informal Know-How Trading." Research Policy 16:291-302. 
725,031 


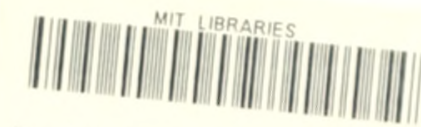

$3908000656848 \quad 6$ 
.

-

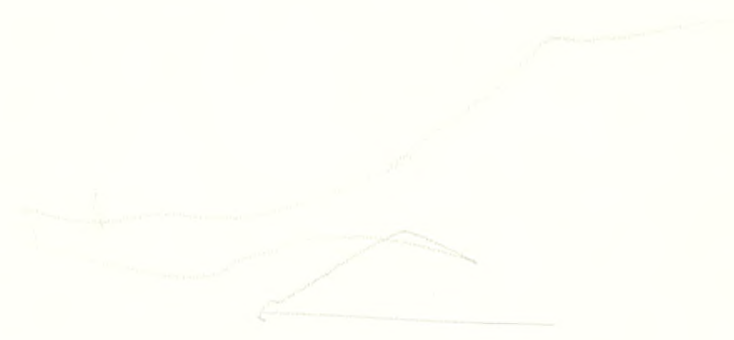

$u_{n}$ 
. 


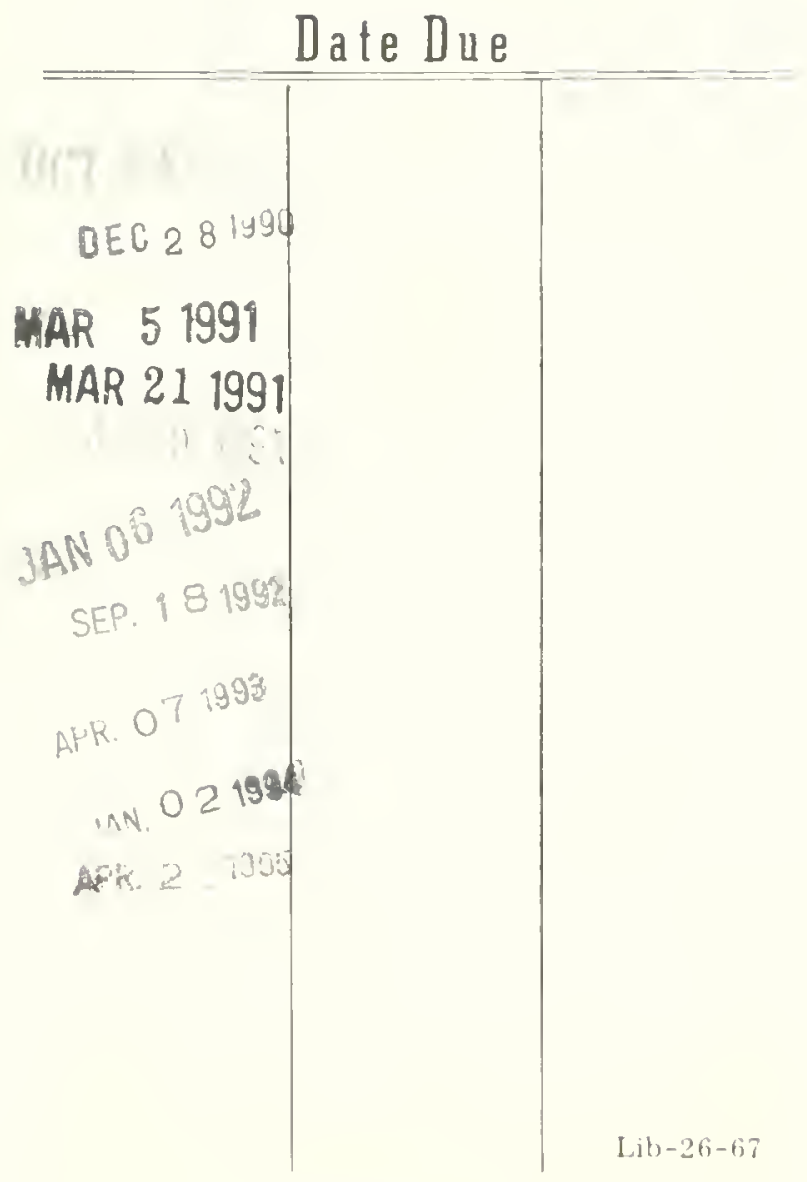




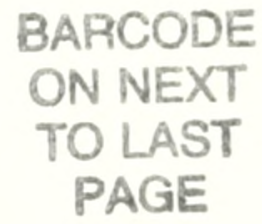


